\title{
Elucidação Parcial da Estrutura de Aminoglucanooligossacarídeos (AGO's) Produzidos Enzimaticamente
}

\author{
Luciana F. Fleuri, Hélia H. Sato \\ Faculdade de Engenharia de Alimentos, Unicamp \\ Jerusa S. Garcia \\ Instituto de Química, Unicamp \\ Telma T. Franco \\ Faculdade de Engenharia Química, Unicamp
}

\begin{abstract}
Resumo: O presente trabalho visou a aplicação da enzima quitinolítica purificada da linhagem Cellulosimicrobium cellulans 191 e da preparação comercial de papaína na hidrólise da quitina coloidal. A quitina coloidal foi caracterizada quanto ao grau de desacetilação e apresentou GD de $14 \%$ por espectroscopia na região do infravermelho. A quitinase purificada hidrolisou a quitina coloidal liberando di-N-acetilquitobiose, enquanto que a preparação comercial de papaína atuando sobre o mesmo substrato formou di-N-acetilquitobiose e tri-N-acetilquitotriose. A estrutura química dos aminoglucanooligossacarídeos foi elucidada por espectrometria de massa.
\end{abstract}

Palavras-chave: Quitinase, papaína, aminoglucanooligossacarídeos, quitina coloidal, espectrometria de massas.

\section{Partial Elucidation of the Chemical Structure of Aminoglucanoligosaccharides (AGO's) Produced Enzymatically}

\begin{abstract}
The aim of this work was the application of purified chitinolytic enzyme from Cellulosimicrobium cellulans 191 and the commercial papain in the hydrolysis of colloidal chitin. The latter was characterized with regard to the degree deacetylation (GD), with a GD of $14 \%$ being obtained using infrared spectroscopy. The purified chitinase hydrolysed the colloidal chitin and formed di-N-acetylchitobiose, while the commercial papain acting on the same substrate formed di-N-acetylchitobiose and tri-N-acetylchitotriose. The aminoglucanoligosaccharides chemical structure was elucidated by mass spectrometry.
\end{abstract}

Keywords: Chitinase, papain, aminoglucanoligosaccharides, colloidal chitin, mass spectrometry.

\section{Introdução}

A quitina é um polímero de $\mathrm{N}$-acetilglicosamina com ligações $\beta-1,4$ encontrada principalmente em carapaças de insetos, parede celular de fungos e crustáceos. É um biopolímero abundante e está geralmente ligado a outros polissacarídeos e proteínas. Refere-se a uma estrutura cristalina altamente ordenada e insolúvel em água ${ }^{[1]}$.

As quitinases (E.C.3.2.1.14), denominadas também de poli $[1,4-(\mathrm{N}$-acetil- $\beta$-D-glicosaminide $)]$ glicanohidrolase, catalisam a hidrólise randômica de ligações glicosídicas $\beta-1,4$ de $\mathrm{N}$-acetil- $\beta$-D-glicosamina (GlcNAc) em quitinas e quitodextrinas ${ }^{[2]}$. São classificadas como endo-quitinases e exo-quitinases. As endo-quitinases clivam de maneira randômica liberando oligômeros como quitotetraose, quitotriose e diacetilquitobiose. Exo-quitinases liberam progressivamente diacetilquitobiose da extremidade não redutora do polímero de quitina. Este último tipo de atividade quitinolítica foi também denominado de quitobiosidase. N-acetilglicosaminidases liberam monômeros de GlcNAc dos oligômeros resultantes da ação de endo e exoquitinases $^{[3]}$.

A hidrólise enzimática de polímeros por preparações comerciais e multienzimáticas para a produção de oligômeros têm sido relatadas por vários pesquisadores. A quitosana, polímero proveniente da desacetilação da quitina, foi hidro-

Autor para correspondência: Luciana F. Fleuri, Faculdade de Engenharia de Alimentos, Unicamp, Caixa Postal 6121, CEP: 13083-970, Campinas, SP, Brasil. 
lisada por lisozima, celulase e hemicelulase $\mathrm{e}^{[4,5]}$, pela preparação comercial Celloviridine G20x que contém atividades de $\beta$-glucanase, xilanase e celulase ${ }^{[6]}$, pela preparação comercial de pectinase ${ }^{[7]}$, por uma preparação comercial de protease neutra ${ }^{[8]}$ e por preparações comerciais de papaína ${ }^{[9,10]}$.

Atualmente têm-se notado um crescente interesse na produção de aminoglucanooligossacarídeos (AGO's) biologicamente ativos através da utilização de enzimas como catalisadores e quitinas e quitosanas como substratos. Neste contexto, é importante ressaltar que métodos enzimáticos podem ser realizados em condições amenas de pressão e temperatura e para a obtenção seletiva de produtos da célula, os quais podem ser recuperados e purificados ${ }^{[2]}$. Os oligômeros formados pela ação de enzimas combinam significativas e convenientes características físico-químicas, biodegradabilidade in vivo, biocompatibilidade e principalmente ação anti-microbiana ${ }^{[11]}$. Quitinas e seus derivados podem ainda apresentar atividade anticâncer, anticolesterêmica, anticoagulante e antioxidante e desempenhar papéis importantes em processos de artrose, doenças neuro-degenerativas, hipertensão, inflamação e diabetes ${ }^{[12]}$.

A literatura descreve que o grau de polimerização e o grau de desacetilação de oligômeros podem causar diversas respostas biológicas. O mecanismo de ação dos AGO's é essencialmente desconhecido e as correlações entre estrutura química e a atividade biológica não foram ainda estabelecidas.

O presente estudo tratou da aplicação da enzima quitinolítica purificada de Cellulosimicrobium cellulans 191 e da preparação comercial de papaína sobre a quitina coloidal visando à produção de AGO's e elucidação da estrutura química dos oligômeros formados por espectrometria de massas.

\section{Material e Métodos}

\section{Preparo dos substratos}

Para a preparação da quitina coloidal, $50 \mathrm{~g}$ de quitina foram tratadas com $200 \mathrm{~mL}$ de $\mathrm{HCl}$ concentrado por 1 hora e em seguida filtradas em lã de vidro. Foram adicionados 2,0 L de água destilada. Após a decantação da quitina a água foi trocada constantemente até atingir $\mathrm{pH}$ ao redor de 7,0 . Posteriormente, a quitina foi centrifugada, seca a $50{ }^{\circ} \mathrm{C}$ e a granulometria padronizada com peneira de 60 mesh, como descrito por Fleuri ${ }^{[13]}$.

A quitina coloidal foi utilizada como substrato para a atuação da quitinase purificada da linhagem Cellulosimicrobium cellulans 191 e da preparação comercial de papaína (Fluka) para a produção de AGO's.

O substrato foi caracterizado quanto ao grau de desacetilação (GD) por espectroscopia na região do infravermelho.

\section{Caracterização do substrato quitina coloidal}

Para a caracterização da quitina coloidal utilizou-se a espectroscopia de absorção na região do infravermelho. A amostra foi misturada com brometo de potássio e prensada sob a forma de pastilhas. Os espectros foram obtidos num espectrofotômetro Bomen, modelo MB, em 40 varreduras. O grau de desacetilação (GD) da quitina foi calculado de acordo com a Equação 1 proposta por Zhang ${ }^{[14]}$.

$$
\mathrm{GD}=100 \times\left(1-\left(\mathrm{A}_{1655} / \mathrm{A}_{3450}\right) / 1,33\right)
$$

sendo $A_{1655}$ e $A_{3450}$ os valores de absorbância para as bandas obtidas, respectivamente, em 1655 e 3450.

\section{Produção de aminoglucanooligossacarídeos (AGO's)}

A hidrólise enzimática para a produção de AGO's utilizando a quitinase da linhagem Cellulosimicrobium cellulans 191 foi realizada conforme metodologia descrita por Ramírez-Coutino et al. ${ }^{[15]}$, com algumas modificações. A enzima $(2,68 \mathrm{U}$ de enzima/mL de tampão fosfato $0,01 \mathrm{M}$, $\mathrm{pH} 7,0)$ purificada por Fleuri ${ }^{[16]}$, foi aplicada sobre a quitina coloidal, na concentração de $6 \mathrm{mg}$ do substrato/mL de enzima, em um reator tipo batelada. A reação, conduzida utilizando $10 \mathrm{~mL}$ da enzima sob agitação, foi mantida a $45^{\circ} \mathrm{C}$ por períodos de até 1 hora.

A hidrólise enzimática para a produção de AGO's utilizando a preparação comercial de papaína (Fluka) foi conduzida como descrito por Kumar et al. ${ }^{[10]}$. A solução de quitina coloidal 1,0\% dissolvida em ácido acético 1,0\% foi tratada com a papaína na razão de 100:1 (p/p). A reação, conduzida utilizando $10 \mathrm{~mL}$ da mistura de reação sob agitação, foi mantida a $37{ }^{\circ} \mathrm{C}$ por períodos de até 3 horas em um reator tipo batelada.

Como branco foi utilizado a mistura de reação no tempo zero. As enzimas foram inativadas em banho em ebulição por 5 minutos e a mistura de reação foi centrifugada a $6000 \mathrm{rpm}$ por 3 minutos.

Os sobrenadantes da mistura de reação foram analisados por espectrometria de massas.

\section{Determinação da estrutura dos AGO's por espectrometria de massas}

As amostras foram analisadas por espectrometria de massas. Inicialmente, as amostras foram liofilizadas e, em seguida redissolvidas em $10 \mu \mathrm{L}$ de uma mistura de água e metanol (v/v 50:50) com TFA 0,1\% (v/v). Alíquotas de 1,0 $\mu \mathrm{L}$ de cada mistura foram aplicadas na microplaca de aço inox do MALDI previamente limpa. As amostras foram secas a temperatura ambiente por alguns minutos. Posteriormente, foi adicionado $1 \mu \mathrm{L}$ da matriz (substância que absorve energia na região ultravioleta) formada por uma solução saturada do ácido $\alpha$-ciano-4-hidroxicinâmico (CHCA) preparada a partir de uma mistura de água e metanol (v/v 50:50) contendo TFA $0,1 \%$ (v/v). A solução de matriz também foi seca a temperatura ambiente. Desta forma, a cristalização da matriz ocorreu espontaneamente. Os espectros de MALDI-TOF MS foram obtidos utilizando espectrômetro de massas marca Micromass, modelo M@LDI-LR (Waters - Micromass, Manchester, UK) em modo positivo (LDI+). Os espectros foram adquiridos adotando os seguintes parâmetros: faixa 
de $\mathrm{m} / \mathrm{z}$ de 400 a 2800 , threshold de 200 , tempo de varredura de 2 segundos, resolução de 10000 empregando o modo "V", MCP de $2000 \mathrm{~V}$ e voltagem de pulso de $2487 \mathrm{~V}$. Cada espectro foi coletado durante 2 segundos e acumulado durante $c a$ 1 minuto. Argônio foi usado como gás de colisão e a energia típica de colisão foi de 34 a $161 \mathrm{eV}$ dependendo da massa do íon. Para ionização foi empregado laser de nitrogênio ( $337 \mathrm{~nm}$ com pulsos de $3 \mathrm{~ns}$ de largura e $20 \mathrm{~Hz}$ ). Os parâmetros instrumentais foram controlados por meio do programa MassLynx, versão 4.1. Todos os espectros foram obtidos no modo refletivo usando calibração externa feita com um padrão de polietilenoglicol (com m/z de 400 a 2500).

\section{Resultados e Discussão}

\section{Caracterização do substrato quitina coloidal}

As técnicas utilizadas para determinar o grau de desacetilação de quitinas e quitosanas após seu isolamento e preparação são: espectroscopia na região do infravermelho, ressonância magnética nuclear de carbono-13, espectroscopia eletrônica ultravioleta, titulação potenciométrica, titulação condutimétrica e ressonância magnética nuclear de prótons $^{[17]}$.

No presente trabalho a quitina coloidal foi preparada a partir de uma quitina bruta tratada com $\mathrm{HCl}$ concentrado, posteriormente seca e peneirada. A amostra foi analisada por espectroscopia na região do infravermelho como ilustrado na Figura 1.

As bandas em 1654,8 e 3450,4 estão associadas à carbonila dos grupos $\mathrm{N}$-acetil e hidroxila, respectivamente, e são utilizadas para o cálculo do GD das quitinas e quitosanas. $\mathrm{O}$ valor de absorbância para a banda de 1654,8 foi de 47,061 e para a banda de 3450,4 foi de 41,192.

Esses valores conduzidos diretamente à Equação 1 forneceram a informação de que a quitina coloidal apresenta um GD de 14\%, inferindo que o substrato apresenta $14 \%$ dos seus resíduos desacetilados ou $86 \%$ dos seus resíduos acetilados.

A metodologia de grau de desacetilação por infravermelho é comumentemente aceita e usada e pode ser considerada confiável, uma vez que quando comparada com outras

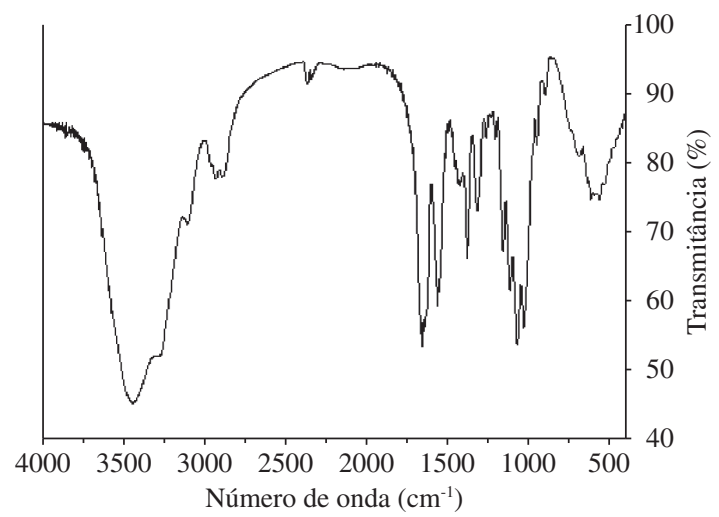

Figura 1. Espectro na região do infravermelho para quitina coloidal. técnicas fornece graus de desacetilação similares aos obtidos por ressonância magnética nuclear de carbono-13, espectroscopia eletrônica ultravioleta e ressonância magnética nuclear de prótons ${ }^{[17,18]}$.

O comportamento químico de polímeros como quitina e quitosana dependem consideravelmente do $\mathrm{GD}^{[14]} \mathrm{e}$ a análise da atuação de enzimas e dos produtos formados são dependentes das características dos substratos.

\section{Produção enzimática dos AGO's e elucidação da estrutura por espectrometria de massas}

\section{Produção de AGO's utilizando quitinase purificada de $C$. cellulans 191 e quitina coloidal}

As massas dos íons gerados, por espectrometria de massas, a partir de padrões de glicosamina estão ilustradas na Tabela 1.

As massas dos íons gerados a partir das amostras foram comparadas com as massas dos íons gerados pelos seus respectivos padrões.

No sobrenadante da mistura de reação contendo quitinase purificada da linhagem C. cellulans 191 e quitina coloidal, incubados a $45{ }^{\circ} \mathrm{C}$ durante por 60 minutos, foi observado um pico de relação $\mathrm{m} / \mathrm{z}$ de 447,28 (Figura 2), o qual corresponde ao íon gerado do padrão de di-N-acetilquitobiose (Tabela 1).

Recentemente várias enzimas quitinolíticas de diferentes microrganismos foram estudadas para a produção de oligossacarídeos.

Muitos autores têm pesquisado a produção de oligômeros provenientes da degradação enzimática de quitinas e quitosanas com diferentes graus de acetilação.

Chen et al. ${ }^{[19]}$ utilizaram dois tipos de quitosanases (ChiA e ChiB) de Aspergillus CJ22-326 para hidrolisar uma quitosana (GD 95\%). O produto de hidrólise da atuação de ChiA sobre a quitosana foi somente GlcN, enquanto que os produtos de hidrólise da atuação de ChiB sobre a quitosana foram $(\mathrm{GlcN})_{3},(\mathrm{GlcN})_{4},(\mathrm{GlcN})_{5}$ e $(\mathrm{GlcN})_{6}$. Com base nos produtos formados os autores sugeriram que a ChiA trata-se de uma exo-quitosanase e a ChiB de uma endo-quitosanase.

Yoon $^{[20]}$ relatou a produção de di-N-acetilquitobiose pela hidrólise da quitina coloidal utilizando uma quitinase obtida do microrganismo Vibrio furnissi.

Liu \& Xia ${ }^{[21]}$ purificaram uma enzima com atividade de quitosanase e de carboximetil celulase de uma preparação comercial de celulase. A enzima atuou sobre quitosana e produziu oligômeros contendo de 1 a 4 resíduos de GlcN e alguns de maior tamanho.

As enzimas $\beta$-N-acetilglicosaminidase e N,N'-diacetilquitobiohidrolase presentes no extrato bruto de Aeromonas sp. GJ-18 produziram N,N'-diacetilquitobiose como o principal produto de hidrólise a partir da quitina. A composição da mistura de quitinooligossacarídeos depende da temperatura de pré-incubação da preparação enzimática bruta ${ }^{[22]}$.

Suginta ${ }^{[23]}$ relatou a hidrólise da quitina coloidal utilizando duas quitinases de Vibrio alginolyticus 283. Ambas enzi- 
Tabela 1. Massa dos íons gerados, por espectrometria de massas, a partir de padrões de glicosamina (GlcN).

\begin{tabular}{ccrrrrrrr}
\hline Oligômeros & Massa do ín $(\mathbf{M})$ & $\mathbf{M}+\mathbf{~ N a}$ & $\mathbf{M}+\mathbf{1} \mathbf{A c} * *$ & $\mathbf{M}+\mathbf{2} \mathbf{A c} * *$ & $\mathbf{M}+\mathbf{3} \mathbf{A c} * *$ & $\mathbf{M}+\mathbf{4} \mathbf{A c} * *$ & $\mathbf{M}+\mathbf{5} \mathbf{A c} * *$ & $\mathbf{M}+\mathbf{6} \mathbf{A c} * *$ \\
\hline GlcN2 & 340,15 & 363,14 & 405,15 & 447,16 & - & - & - & - \\
GlcN3 & 501,22 & 524,21 & 566,22 & 608,23 & 650,24 & - & - & - \\
GlcN4 & 662,28 & 685,27 & 727,28 & 769,29 & 811,30 & 853,31 & - & - \\
GlcN5 & 823,35 & 846,34 & 888,35 & 930,36 & 972,37 & 1014,38 & 1056,39 & - \\
GlcN6 & 984,42 & 1007,41 & 1049,42 & 1091,43 & 1133,44 & 1175,45 & 1217,46 & 1259,47 \\
\hline
\end{tabular}

$\mathrm{Na}^{*}=$ Sódio; e Ac** = grupos acetil.

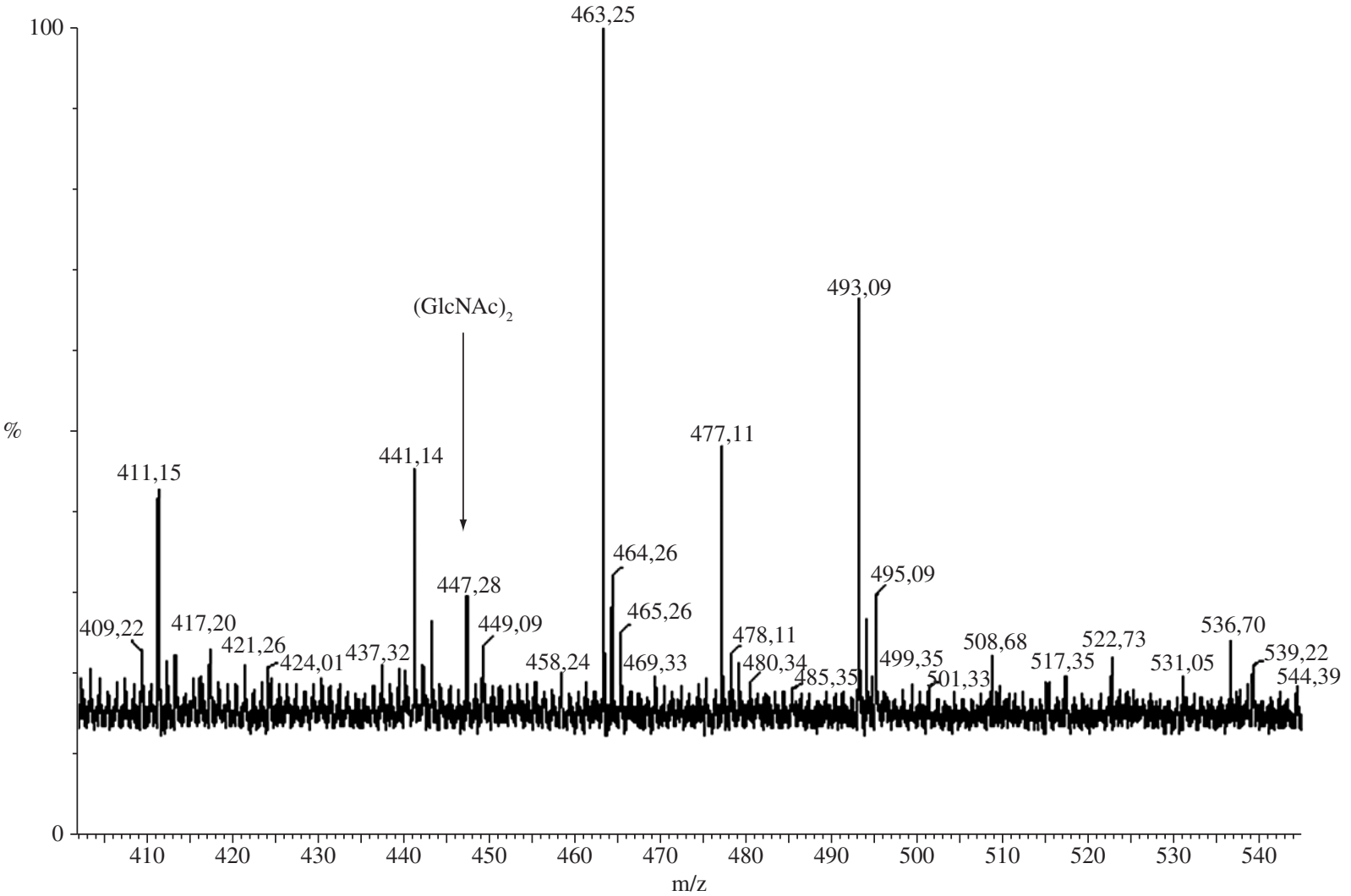

Figura 2. Espectro de massas do hidrolisado da quitina coloidal pela enzima de C. cellulans 191 obtido após 60 minutos a $45^{\circ} \mathrm{C}$ (região de m/z entre 410 a 540 ).

mas foram capazes de formar $(\mathrm{GlcNAc})_{2}$ e $(\mathrm{GlcNAc})_{3}$ após 60 minutos a $37^{\circ} \mathrm{C}$.

Os produtos acetilados $\mathrm{N}$-acetilglicosamina e $\mathrm{N}$-acetilquitoligossacarídeos foram produzidos a partir da quitina coloidal pelo uso do extrato enzimático bruto obtido do Paenibacillus illinoisensis KJA-424. As análises realizadas por HPLC permitiram verificar que a produção de GlcNAc aumentou continuamente durante a incubação, enquanto a produção dos oligômeros de GlcNAc diminuiu. A maior produção de GlcNAc foi obtida após 24 horas de incubação, sendo que foram obtidos quitobiose, quitotriose, quitoheptose e quitooctose ${ }^{[24]}$.

No presente estudo constatou-se a produção de di-N-acetilquitobiose $\left[(\mathrm{GlcNAc})_{2}\right]$ a partir de quitina coloidal (GD 14\%) e quitinase purificada do microrganismo C. cellulans 191 , a $45^{\circ} \mathrm{C}$ após 60 minutos de reação em reator tipo batelada. $\mathrm{O}$ oligômero apresenta estrutura química GlcNAc-GlcNAc.
Produção de AGO's utilizando preparação comercial de papaína e quitina coloidal

Os sobrenadantes da mistura de reação contendo a preparação comercial de papaína e quitina coloidal (GD 14\%), incubados a $37{ }^{\circ} \mathrm{C}$ durante $5,15,30,45,60,120$ e 180 minutos, foram analisados por espectrometria de massas. Após 5 minutos de reação não foi observado nenhum íon com relação $\mathrm{m} / \mathrm{z}$ correspondente aos padrões de oligômeros (Tabela 1). Foi observado após 15 minutos de reação, um pico de relação $\mathrm{m} / \mathrm{z}$ de 447,28 correspondente ao di-N-acetilquitobiose $\left[(\mathrm{GlcNAc})_{2}\right]$ e outro com relação m/z 650,29 correspondente tri-N-acetilquitotriose $\left[(\mathrm{GlcNAc})_{3}\right]$ (Figura 3 ).

Nos hidrolisados da quitina coloidal pela preparação comercial de papaína obtidos após 30, 45, 60, 120 e 180 minutos de reação também foram encontrados picos de relação $\mathrm{m} / \mathrm{z}$ referentes ao (GlcNAc) e ao (GlcNAc). Após 30 minutos de reação foram obtidos picos de m/z de 447,15 [(GlcNAc) $)_{2}$ ] e $650,29\left[(\mathrm{GlcNAc})_{3}\right]$; após 45 minutos, picos de $\mathrm{m} / \mathrm{z}$ de $447,10\left[(\mathrm{GlcNAc})_{2}\right]$ e 650,29 [(GlcNAc $\left.)_{3}\right]$; após 60 minutos, 


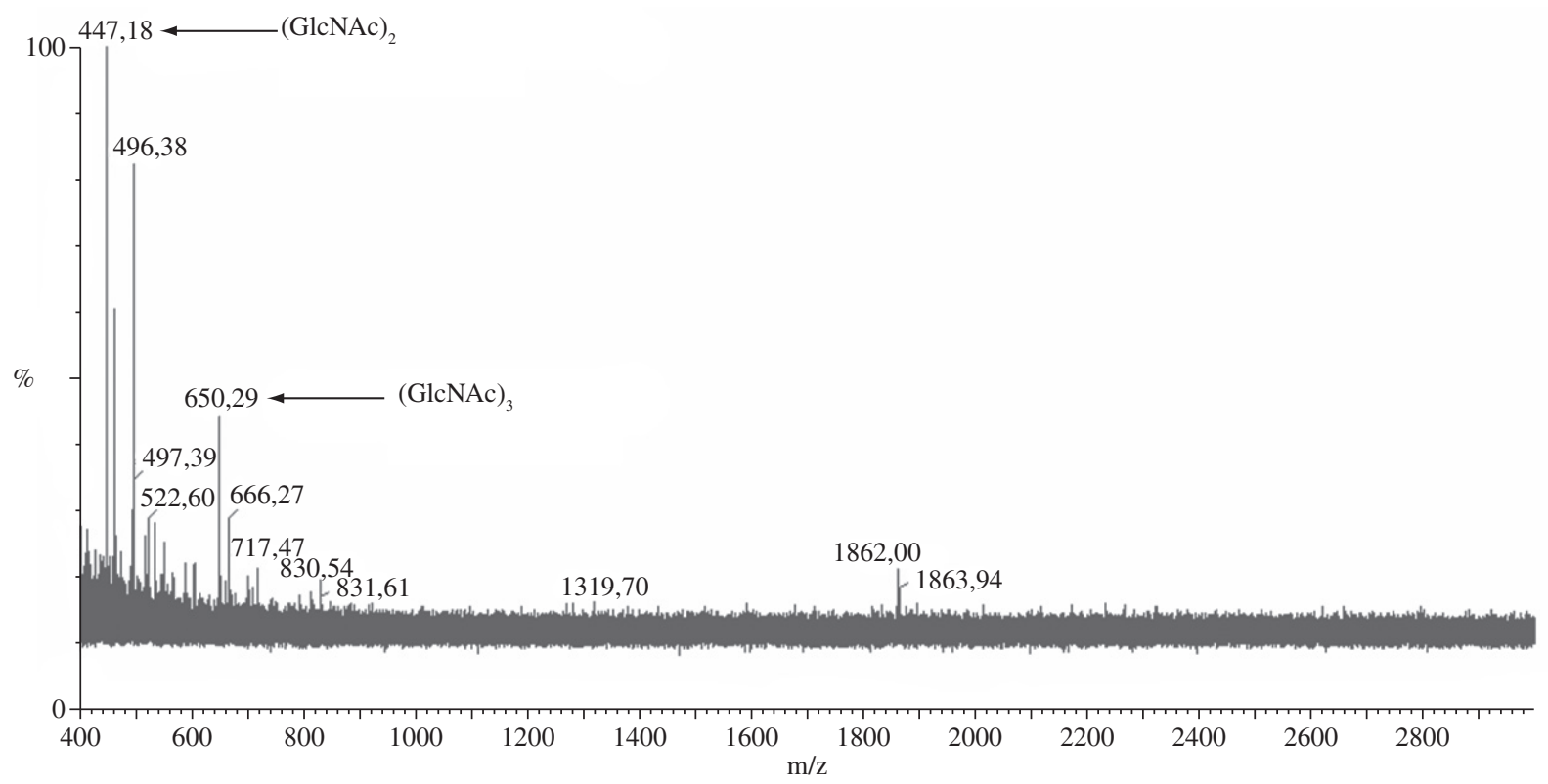

Figura 3. Espectro de massas do hidrolisado da quitina coloidal pela preparação comercial de papaína obtido após $15 \mathrm{~min}$ a $37^{\circ} \mathrm{C}$ (região de $\mathrm{m} / \mathrm{z}$ entre 400 a 2800).

picos de $\mathrm{m} / \mathrm{z}$ de $447,23\left[(\mathrm{GlcNAc})_{2}\right]$ e $650,29\left[(\mathrm{GlcNAc})_{3}\right]$; após 120 minutos, picos de $\mathrm{m} / \mathrm{z}$ de $447,25\left[(\mathrm{GlcNAc})_{2}\right]$ e $650,36\left[(\mathrm{GlcNAc})_{3}\right]$ e após 180 minutos, picos de $\mathrm{m} / \mathrm{z}$ de $447,25\left[(\mathrm{GlcNAc})_{2}\right]$ e $650,38\left[(\mathrm{GlcNAc})_{3}\right]$.

Zhang \& Neau ${ }^{[25]}$ estudaram a hidrólise de quitosanas com diferentes graus de desacetilação (GD 76 e 92\%) utilizando como agente catalisador a preparação comercial emulsina. A formação de oligômeros foi atribuída à uma quitosanase presente na preparação enzimática.

Chiang et al. ${ }^{[26]}$ utilizaram uma preparação comercial de ficina para hidrólise de quitosanas com diferentes graus de acetilação. Os autores verificaram a presença de uma quitosanase, a qual seria responsável pela produção de quitosanas de baixa massa molecular a partir de substratos maiores.

Lin et al.$^{[9]}$ relataram a utilização de papaína para a preparação de oligômeros utilizando quitosana com GD 86,4\% e quitina com GD 50\%.

Outro estudo mostrou que a preparação comercial de papaína proveniente de Papaya latex foi capaz de formar dímeros $(\mathrm{m} / \mathrm{z} 376,6)$, trímeros (m/z 530,8 e 561,4), tetrâmeros (m/z 760,5), pentâmeros (m/z 954,8) e hexâmeros (m/z 1083,2 e 1114,6$)$ a partir de uma solução de quitosana $1,0 \%{ }^{[10]}$.

A papaína (E.C. 3.4.22.2) catalisa a hidrólise de ligações peptídicas de proteínas. Alguns autores sugerem que as papaínas são enzimas de atividades não específicas, e por isso, podem ser utilizadas para a hidrólise de quitosanas; enquanto outros, sugerem a existência de enzimas contaminantes que atuariam em seus substratos específicos.

O presente estudo relata pela primeira vez a hidrólise da quitina coloidal por uma preparação comercial de papaína proveniente de Carica papaya. Foram obtidos oligômeros de baixa massa molecular, (GlcNAc) $)_{2}(\mathrm{~m} / \mathrm{z} 447)$ e $(\mathrm{GlcNAc})_{3}$ $\left(\mathrm{m} / \mathrm{z}\right.$ 650), após de 15 minutos de reação a $37{ }^{\circ} \mathrm{C}$, em rea- tor tipo batelada. Foram também detectados os mesmos oligômeros após 30, 45, 60, 120 e 180 minutos de reação. Os oligômeros (GlcNAc) $)_{2}$ e (GlcNAc) ${ }_{3}$ apresentam respectivamente, as seguintes estruturas química: GlcNAc-GlcNAc e GlcNAc-GlcNAc-GlcNAc.

\section{Conclusão}

A quitina coloidal apresentou GD de 14\% por espectrometria na região do infravermelho e foi hidrolisada pela quitinase purificada da linhagem Cellulosimicrobium cellulans 191 e pela preparação comercial de papaína formando AGO's. O produto da ação da quitinase sobre a quitina coloidal foi identificado como sendo um di-N-acetilquitobiose com estrutura química GlcNAc-GlcNAc, enquanto que os produtos da ação da preparação comercial de papaína sobre o mesmo substrato foram di-N-acetilquitobiose e tri-N-acetilquitotriose, com as respectivas estruturas químicas, GlcNAc-GlcNAc e GlcNAc-GlcNAc-GlcNAc. A produção enzimática de AGO's com atividades biológicas em potencial amplia o campo de utilização das enzimas estudadas, assim como da quitina, a qual apresenta seu uso limitado frente à sua biodisponibilidade e abundância.

\section{Agradecimentos}

À FAPESP pelo apoio financeiro.

\section{Referências Bibliográficas}

1. Majeti, N. \& Kumar, R. - React. Funct. Polym., 46, p.1 (2000). 
2. Fleuri, L. F. \& Sato, H. H. - Quim. Nova, 5, p.871 (2005).

3. Lin, H.; Wang, H. Y.; Xue, C. H.; \& Ye, M. - Enzyme Microb. Technol., 31, p.588 (2002).

4. Aiba, S. - Carbohydr. Res. 261, p.297 (1994).

5. Aiba, S. \& Muraki, E. - Advan. Chitin Sci., 1, p.197 (1996).

6. Il'ina, A. V.; Tkacheva, Y. V. \& Varlamov, V. P. - Appl. Biochem Microbiol., 38, p.112 (2002).

7. Kittur, F. S.; Kumar, A. B. V.; Varadaraj. M. C. \& Tharanathan, R. N. - Carbohydr. Res., 340, p.1239 (2005).

8. Li, J.; Du, Y.; Yang, J.; Feng, T.; Li, A. \& Chen, P. - Polymer Degr. Stab., 87, p.441 (2005).

9. Lin, H.; Wang, H. Y.; Xue, C. H. \& Ye, M. - Enzyme Microb. Technol., 31, p.588 (2002).

10. Kumar, A. B. V.; Varadaraj, M. C.; Gowda, L. R. \& Tharanathan, R. N. - Biochem. J., 391, p.167 (2005).

11. Hirano, S. - Polymer Int., 48, p.732 (1999).

12. Ngo, D. N.; Kim, M. M \& Kim, S. K. - Carb. Polymers, article in press (2008).

13. Fleuri, L. F. - "Produção de $\beta-1,3$ glucanases, proteases líticas e quitinases por microrganismos e aplicação na lise de leveduras", Dissertação de Mestrado, Universidade Estadual de Campinas, Brasil, 2003.

14. Zhang, Y.; Xue, C.; Xue, Y.; Gao, R. \& Zhang, X. Carbohydr. Res., 340, p.1914 (2005).

15. Ramírez-Coutino, L.; Marin-Cervantes, M. D.; Huerta, S.; Revah, S. \& Shirai, K. - Process Biochem., 41, p.1106 (2006).
16. Fleuri, L. F. - " $\beta-1,3$ glucanases, proteases e quitinases: produção, purificação e aplicações", Tese de Doutorado, Universidade Estadual de Campinas, Brasil, 2006.

17. Lima, I. S. - "Quitosanas e Quitosanas química e morfologicamente modificadas com anidrido succínico - Propriedades, Adsorção e Termoquímica”, Tese de Doutorado, Universidade Estadual de Campinas, Brasil, 2005.

18. Duarte, M. L.; Marvão, M. R.; Ferreira C. \& Rocha, J. Int J Biol Macromol., 28, p.359 (2001).

19. Chen, X.; Xia, W. S. \& Yu, X. B. - Food Res. Internat., 38, p.315 (2005).

20. Yoon, J. H. - Enzyme Microb. Technol., 37, p.663 (2005).

21. Liu, J. \& Xia, W. S. - Biochem. Eng. J., 30, p.82 (2006).

22. Kuk, J. H.; Jung, W. J.; Jo G. H.; Kim, K. Y. \& Park, R. D. - World J. Microbiol. Biotech., 22, p.135 (2006).

23. Suginta, W. - Enzyme Microb. Technol., 41, p.212 (2007).

24. Jung, W. J.; Souleimanov, A.; Park, R. D. \& Smith, D. L. - Carbohydr. Polym., 67, p.256 (2007).

25. Zhang, H. \& Neau, S. H. - Biomaterials, 22, p.1653 (2001).

26. Chiang, C. L.; Chang, C. T. \& Sung, H. Y. - Enzyme Microb. Technol., 32, p.260 (2003).

Enviado: $18 / 06 / 08$

Reenviado: $10 / 12 / 08$

Aceito: $15 / 12 / 08$ 